\title{
THE ENVIRONMENTAL REALITY OF THE NAGA RIVER IN CAMARINES SUR, PHILIPPINES: THE PERCEPTIONS AND EXPERIENCES OF THE RIVERSIDE HOUSEHOLDS
}

\author{
Mariel R. Estrella Ph.D. \\ School of Graduate Studies, Partido State University
}

Article DOI: https://doi.org/10.36713/epra8422

DOI No: 10.36713/epra8422

\begin{abstract}
The present study documented the early and current state of the Naga river by categorizing it in four decades of development. The timeline helped the respondents visualize the ideal state of the river which for them is worth conserving for the future generations. The study also identified the perceptions and experiences of the riverside households on the stresses and shocks, fears and anxiety, and benefits derived. The identification of environmental stresses and shocks constructed a reality map or a perception of environmental reality based on their experiences. Focus Group Discussion was conducted with 79 respondents in 5 of the 11 riverside barangays. These represented the upstream, midstream, and downstream barangays. Key Informant Interview was done with 19 key people of the study. Results of the FGD show that flood brought about by the typhoons and the heavy rains are their biggest shocks and stresses. As to fears and anxiety, the fear of floods had the highest and the least was the loss of a religious tradition. This concurs on the findings that floods are the primary environmental shock as perceived by the respondents. The identification of benefits determined the reasons on what holds the community to the river despite the threats. Topmost among the benefits was the river as source of livelihood and the least benefit was for recreation.

KEYWORDS: Naga River, environmental reality, environmental stresses and shocks, fears and anxiety of the river,

benefits of riverside households
\end{abstract}

The Naga river is located in Naga City, a city situated 377 kilometers southeast of Manila in the Philippines. Naga river traverses the city center. It stretches about 2.8 kilometers winding through 11 of the 27 barangays of the city. The Naga River is a water body that bisects the Naga City center. The river system originates from Mount Isarog in the north and drains to the Bicol River in the south.

Naga river used to be abundantly endowed with aquatic resources and people used to enjoy its bounty. The people's attitude and behavior towards the river are believed, however, to contribute to what the river is today. This why sharing their past experiences with the river helps to understand the present reality and to predict what might happen in the future. The environmental reality of Naga river, then, is the people's experiences with the river as it relates to their way of life.
Perceptions of the river vary among individuals. Tarranum, F. et.al. (2018) stated that people perceive the river Yamuna in India in a non-scientific way. They perceive the river through their senses (sensorial) and according to the uses of the river (heuristic). The perception of respondents on sources of pollution in the river is shaped by personal experiences. The risk perception on the pollution in the river due to anthropogenic activities was found to be linked to their direct dependence on the river for their daily needs. The children in the study of Tunstall, S, et.al. (2007), on the other hand, recognized the aesthetic appeal of the river and the dangers of pollution. They also recognized the river as their play area giving them varied, adventurous and manipulable play opportunities. But they expressed they want the river to be cleaner, safer, more accessible, and properly managed. 
In this study, getting the perceptions and experiences of the riverside households on the early and current state of the Naga river is significant to describe the ecological value of the river. It is in this light that the study established the timeline of the river in four decades of development through the perceptions and experiences of the respondents. It determined the 1.) environmental stresses and shocks, 2.) fears and anxiety, and 3.) benefits of households residing along the riverside. This highlights their perception why they stay in the riverside despite the stresses and shocks and their fears and anxiety of an impending disaster.

\section{MATERIALS AND METHODS Subjects and Setting}

The study focused on 5 of the 11 barangays along the Naga River which were chosen based on location. The representative upstream barangay is Balatas, midstream barangays include Penafrancia, and San Francisco, and downstream barangays are Sabang, and Tabuco. All are classified as urban barangays with the majority of the land allocated to residential, commercial, and agricultural uses.

Figure 1.Location map of Naga City and Naga River in Camarines Sur, Philippines.

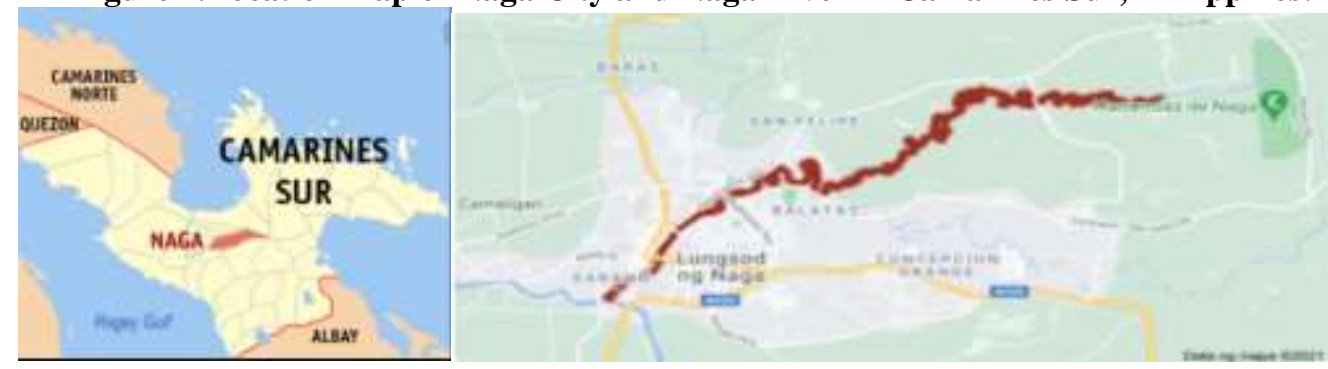

Source: https://www.google.com

\section{Focus Group Discussions and Key Informant Interview}

This qualitative research made use of Focus Group Discussion (FGD) and Key Informant Interview (KII). FGD in each of the five riverside barangays were conducted to obtain data on the environmental reality of the Naga river through the perceptions and experiences of the respondents about the river. Focus questions were prepared and consensus building was reached in cases where responses were varied. A total of 79 respondents composed of barangay officials and sectoral representatives like health, business and industry, academe, transport, and senior citizens participated in the FGD. Further validation was done through Key Informant Interview (KII) with 19 government officials, barangay officers, and residents along the riverbank.

Qualitative data were generated, described, and analyzed. A historical timeline of the existence of the Naga River showing the critical interaction of the Naguenos and river was done through the FGD. Respondents narrated their environmental stresses and shocks, fears and anxiety of the river, and their benefits from the river. Cluster analysis was used to group and characterize the fears and anxiety and the benefits. Secondary data from internet sources, technical articles and other publications were likewise used in the discussion of results.

\section{RESULTS AND DISCUSSION \\ The Four Decades of the River \\ Decades of Existence of the Naga river}

The historical timeline of the Naga river shows the critical interaction of the Naguenos and the Naga River. The interactions could be characterized in a continuum of nurturing to abusing, and cherishing to exploiting. There are four major decades of development that this study distinctively categorized.

The early decades 1940s-1950s are the Decades of River Excursions; 1960s-1970s are the Decades of Challenges and Uncertainties; 1980s-1990s are the Decades of River Degradation; and the 2000s to present are the Decades of Action.

The respondents revealed that the Decades of River Excursions showed how people enjoyed the early years of the river. Naga river then had a very high recreational value. People enjoyed the view of the thick trees and plants on the riverbank and they bathed in the crystal clear waters where rocks and fishes can be seen on the riverbed. The rich water resources of the Naga river was a source of livelihood to many residents along the river. The fish catch were either used for food or were sold to augment the family income. Fishes that were abundant were tilapia (Oreochromis niloticus/Tilapia nilotica), talusog/snakehead murrel (Chiana strata), and puyo/climbing perch (Arabas testudineus). 
A critical development during these decades was when people changed the natural course of the river. In an FGD, respondents believed that the river was straightened instead of its natural curved contour as early as 1639 by Bishop Francisco Gainza in his effort to build straight and smooth roads in the central part of the city. Bordado (2011) affirmed that the $1.5 \mathrm{~km}$ stretch of the river bisects two districts of the Naga City, the former Ciudad de Nueva Caceres "the northern district was the seat of the local civil Spanish government and the Catholic ecclesiastical entity whose power and influence, according to historical records, spanned as far as Nueva Ecija in Central Luzon. On the other hand, Chinese merchants and artisans, along with the natives, congregated in the southern district."

( para.2.)

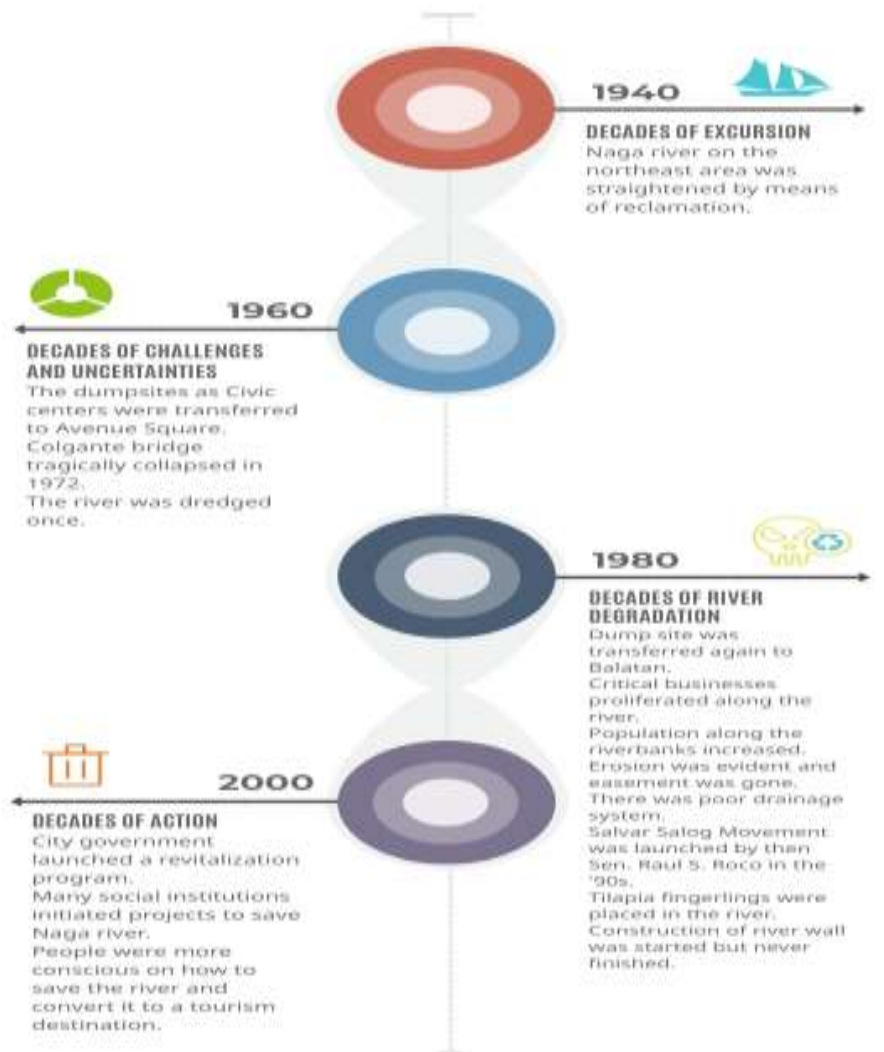

Figure 2. Historical timeline of Naga river.

The Decades of Challenges and Uncertainties were between the 1960s-1970s. Respondents expressed that due to the growing garbage collection in the city, the Civic Center was made the first dump site. Few years after, the dump site was transferred to Magsaysay area now the Avenue Square. Towards the 1970s, the river had floating branches of trees, logs, dead animals, and garbage. These were attributed to the messy dump site and the careless attitude of the riverside households and the businessmen who practically throw their waste on the river. Erosion was evident and the river was dredged once to deepen the river for the fluvial procession of the Virgin of Penafrancia. In was also in this decade that the Naga river started to get smelly, muddy, and the dark brown water flowed slowly in its high and low tide. The riverside residents were uncertain of what future the river holds for them.

The decade was made bleaker by the tragic collapse of Colgante bridge on September 16, 1972 where about 140 devotees of INA perished. Yuboco (2011) in his online article "Pictures of the river in the 70s" described how the rickety wooden bridge fell on the afternoon of the fluvial procession. He described the dark moment with sounds of breaking timber and thundering shouts of fright and panic that filled the whole area around and under the bridge.

The Decades of River Degradation (1980s-1990s). The transfer of the dump site along Magsaysay Avenue to barangay Balatas caused the river degradation. Respondents of the FGD identified that the bulk of floating matters on the river came from the upstream 
barangay Balatas which is so called the "Smokey Mountain" of Naga City. The study further relates the river degradation to the increasing population in the city particularly along the riverbanks. As the population increased, there were more residential houses and business establishments built near the riverbank mostly with poor drainage system. In fact, the FGD respondents confirmed that most households did not construct septic tanks instead toilet and kitchen wastes flow directly to the river. The study further noted that in this decade, many business establishments were opened very near or even along the riverbank. Among the identified critically harmful establishments to the state of the river were the Alatco/Philtranco bus terminal located in barangay San Francisco, fishing business in barangay Tabuco, junk shop, calesas, lumber, eateries and piggeries in Dayangdang. Respondents in the FGD particularly expressed their concern on the flowing gasoline residue and oil spill coming from the bus terminal which they connected to the pollution and the oily and muddy taste of the fishes. In the 5 FGDs conducted, the respondents narrated the malpractice of a local sludge extractor company. There was a time in this decade that the sludge collected was drained in the Naga river. It was done once but it was the major pollutant in the river.

Easement problem was also evident because of the heavy erosion brought about by typhoons and the natural course of the river. While the respondents know that they have 3-4-meter easement from the riverbank, there was a confusion as to where it is counted because of the heavy erosion over the years.

Significant initiatives were done to address the degradation problem. Among these were the "Salvar Salog Movement" initiated by then Senator Raul S. Roco in 1993. To increase the fish catch, tilapia fingerlings were released in the river. To address erosion problem, river wall locally called "riprap" was likewise started although unfinished in most parts. Despite these efforts, however, the respondents specifically cited their fear on the damaged river wall along the Sto. Nino Memorial Park. For them, the cemetery residues negatively impact the quality of the Naga river. It is also in these decades that water appeared turbid, greenish and dark brown coupled with a smell of gasoline, fish, and mud. Fish catch dwindled and the fishes started to die. Those who took a bath or swam in the river got skin diseases.

With a common vision of rehabilitating the Naga River, the Decades of Action (2000s to present) show the effort of the City Government and other concerned groups to revitalize the river. The Revitalization program was launched by the City Government of Naga and researches to improve the condition of the
Naga river were conducted by mostly academe, NGOs, and other international organizations.

Among the significant initiatives of the City Government was the Reactivation of the Salvar Salog Clean Up Drive which is a regular clean-up of the Naga River that started in the early 1990s. A major effort to revitalize the river was the Feasibility Study on the Integrated Naga River Revitalization Project (INRRP) in 2012. Supported by the CDIA, it identified viable subprojects like River Walk, Flood Mitigation and Drainage, Sanitation, Solid Waste, and Isla Sison as a relocation site. Naga river was also identified as a means of transport and a tourism destination. Another was the relocation of the riverside residents particularly under the bridge of Magsaysay, Colgante, Delfin Rosales, and Tabuco. At present there are four relocation sites in Naga City namely Sitio Salunguigui in Cararayan; Zone 9 in Green Park, Pacol; San Rafael, Balatas; and Pagdaicon, Mabolo. (Naga Smiles Magazine, Vol. 1, No. 1, Sept. 2010 and HSDO)

FGD results also show that during the decades of action, the residents were more conscious on how to save the river and they are looking forward to converting the Naga river as a formal means of transport and as a Tourism destination. They noted that in mid 2000s, water became much clearer with less floating matters. The odor is more tolerable than the previous decades.

This timeline largely shows the attitude, motivation and cultural convictions of the riverbank residents where they turned the current state of the river into their future perceptions. The respondents were reconnecting with the Naga river being the immediate stewards of the environment.

\section{Perceptions and experiences of the riverside households}

Perception is a personal thing, it is a person's map of reality. This reality map is a result of the person's own values, beliefs, and experiences. Through perception, a person becomes aware of his reality and gain understanding of a certain phenomenon.

\section{Environmental stresses and shocks}

The identification of environmental stresses and shocks is designed to construct a reality map or a perception of environmental reality based on the experiences of the respondents.

The FGD sessions in the five barangays indicated that the biggest environmental shock and stress is the flood caused by the regular typhoons and heavy rains. The general adverse effects on the respondents are on their lives and properties. Loss of lives was noted where 5 were drowned in Penafrancia and about 5 and 
10 became sick in Tabuco and Sabang, respectively, due to the river floods.

Properties include houses, businesses, and domestic animals. The study shows that $60-75 \%$ of the businesses are affected particularly in barangay Penafrancia, and Sabang. The affected businesses were bamboocraft, piggery, lumber, junk shop, and car repair shop. Damage to property is most severe with houses made of light materials which were washed away in Sabang, Penafrancia and San Francisco. This also included the loss of domestic animals like pigs, dogs, chickens, and horses of the respondents in barangay Tabuco, and Penafrancia.

These barangays were the same areas confirmed by DDRMO as Flood Prone Barangays, from where populations at risk are not only by those who lived by the riverbanks but the whole barangay. On the other hand, DDRMO has developed infrastructural mitigation to minimize the effect of floods as well as updated Flood Hazard Maps. (SDP-DDRMO 2012). Other researches further support the findings of this study. Guarin (2008) described that the flooding that occurs in the low lying areas of Mabolo and Triangulo in Naga City as seriously jeopardizing by obstructing the residents in terms of their mobility, provision of medicines, food and relief from outside. The damage surveys and rapid assessments done by the Department of Social Work Welfare (DSWD) and the Office of the City Mayor (1998) show that the number of casualties reported were 10 persons perished by drowning, hypothermia, cardiac arrest and fetal death as a result of Typhoon Loleng. The reported damaged houses were 8,634 from which nearly 1,700 or 16 percent were reported as totally damaged. Typhoon Unding and Yoyong struck the city in 2004 and a total 1,974 houses were reported as totally damaged, 1,026 as heavily damaged, and some 8,218 partially damaged. Displaced residents accounted to nearly 55,000 (almost 11,218) and 4 casualties (cited CDMO, 2004).

\section{Fears and Anxiety}

The drawing of fears and anxiety is designed to establish perceptions of what may happen in the future as manifested by threats of which is a consequence of environmental stresses and shocks. Among the fears, the fear of floods had the highest $88 \%$ and the least $12 \%$ is the loss of a religious tradition. This data concur with the findings that floods are the primary environmental shocks as perceived by the respondents.

The data also show that fear of losing a religious tradition, although among the least feared and cause of anxiety, connotes a strong cultural attachment to the religious event. Its loss due to a dying river provides a strong bio-physical and socio-cultural connectivity among the communities.

In the FGDs, the respondents expressed high level of apprehension due to the occurrence of floods. The respondents further clustered their sub fears which are 1.) Threat to life. The respondents experienced family members or neighbors drown, got illnesses and diseases due to flood, and sometimes snakes settle in their houses when the water subsides. 2) Loss of livelihood. This results to no income to buy basic needs and minimal or no food for the family. 3)Loss of shelter. This compels them to stay in evacuation areas with poor facilities and oftentimes result to the spread of diseases, and 4) Soil erosion. This results in destruction of easement, riverbanks, riverwalls and rails. Soil erosion also cause the river to become shallow making it impossible for the annual fluvial procession to proceed during low tide. 


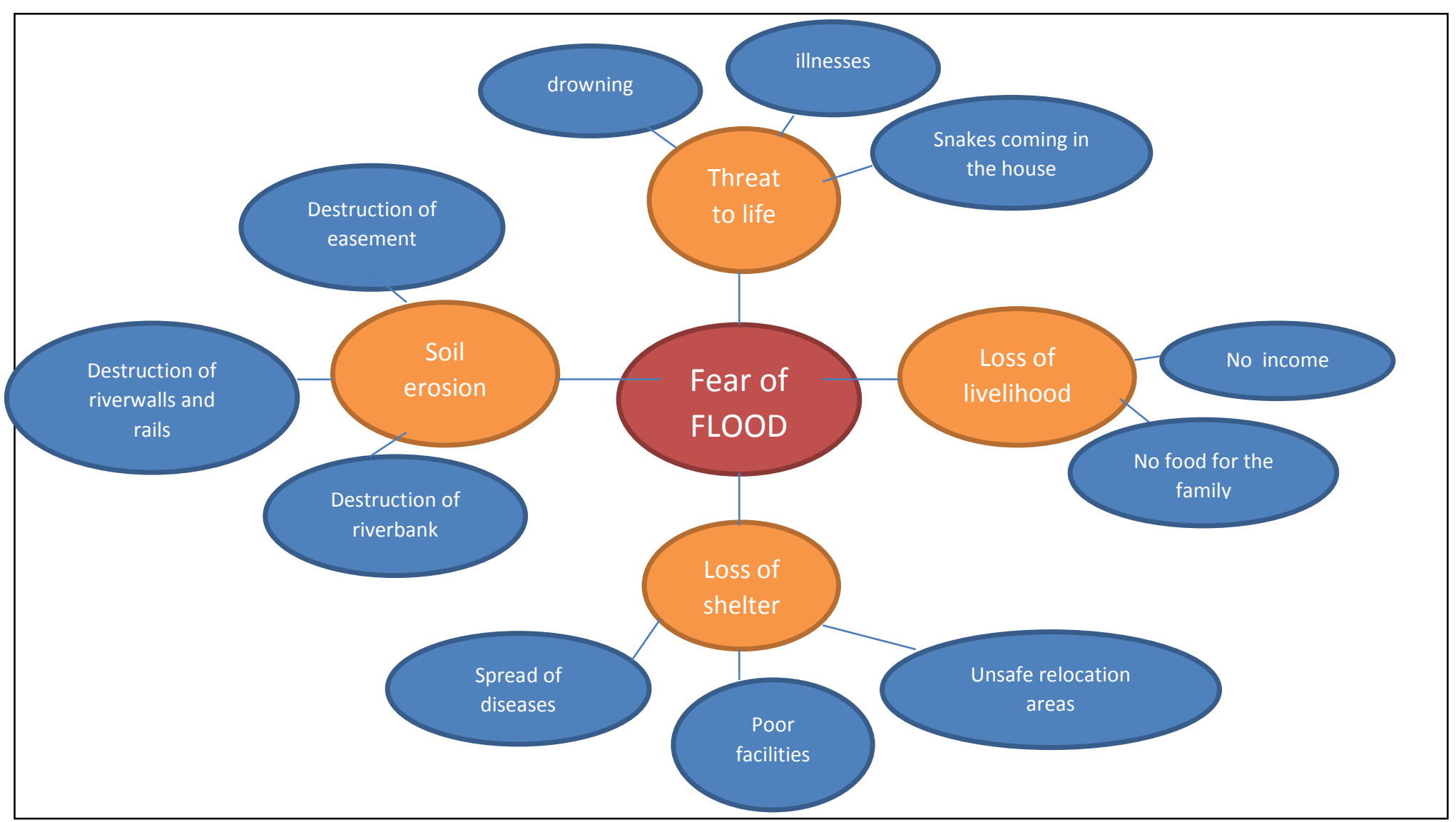

Figure 3. Cluster Diagram of the Fears/Anxiety of the Respondents

However, the study of Guarin (2008) stated that "the high recurrence of floods and winds associated to the annual season, people in Naga seem to have generally accepted them as a fact of life. Flooding is not really perceived as a serious problem and much more a risk to reckon with for those along the flood prone areas. Guarin's findings is further supported by Reganit (2005) that floods are perceived as a nuisance than a catastrophe. People would stay in the area due to their livelihood and children whose schools are nearby. She furthered that communities has developed coping mechanisms to protect and cope with the effects of flood. The coping mechanisms were focused on preparedness, response and recovery measures that deals with the floods and the social coping mechanism to strengthen the community's social structure."

The findings also implies the resiliency of riverbank residents who displayed social interactivity, which characterizes their social and environmental values. They rebuild their lives, their houses and properties as commercial center reopens. The Bicolano spirit of close neighborhood, kinship and camaraderie is seen, which was also an observed interaction even during focus grouped discussions.

Their gestures communicate familiarity of each other's' experience by the river. 'In general the cultural attitude assumed to cope with the risk derived from flooding, strong winds and typhoons are based on the personal capacity of the individual to alleviate, prevent or bear the losses in accordance with their own financial means" (Guarin (2008) p.91 cited ADPC (2001)

These characters while it can initially be viewed as indications of resiliency, it should not however be implied as manifestations of sustainability. The community may rebuild their homes, continue with their livelihoods and consider floods as a fact of life but may never change their ways of looking at the river as one big dumpsite.

\section{Benefits of community folk residing along the riverside.}

The identification of benefits determined the reasons what holds the community to the river despite 
the threats. This facilitates the analyses of the to view different perspectives of its relevance in their community's relationship with the river, allowing them lives.

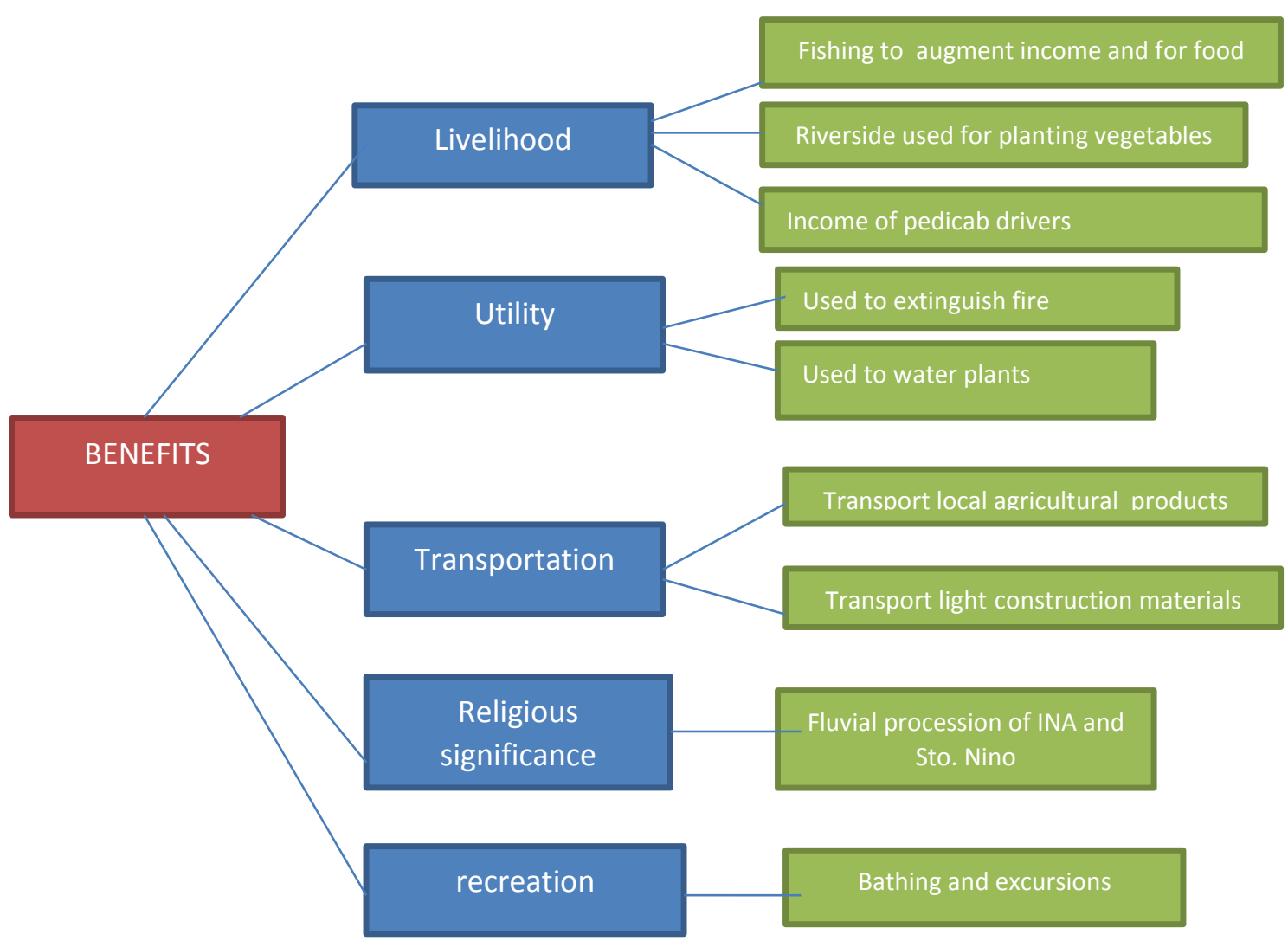

Figure 4. A cluster diagram showing the benefits derive by the respondents from Naga river.

Topmost among the benefits were livelihood, utility, transportation, religious significance, and recreational value.

Livelihood is one of the reasons why respondents do not leave the riverside. The riverside households regard the river as their source of livelihood and sustenance. Respondents from Barangay Sabang for example, make use of vacant spaces by the riverside to plant vegetables. Other respondents who are dwellers of the riverside find their location convenient for their job as pedicab drivers with a minimum income of two to three hundred pesos a day to feed their family. Other respondents narrated their fishing experience to augment their income despite the unusual taste of mixed mud and gasoline.

Nonetheless, the respondents also expressed that the riverine system aids them in transporting goods like nipa (Nypa fruticans), bamboos, palay, and other commodities coming from suburbs of Naga, like Camaligan, Magarao, Gainza, Milaor, Minalabac or places as far as Libmanan and Cabusao. They used pump boats (known as lantsa) in the 60's which is used to transport agricultural products, goods, merchandise and passengers or simple bamboo raft (barsa) or banana raft utilized to facilitate day to day activities by the river.

The use of the Naga river extends even during house fire. In Bgy.Tinago, a resident acknowledged the river as the main source of putting off the fire which was a benefit they derived from it. In Bgy. San Francisco in 2006, a "Fire-Out" was declared with the help of pails of water from the Naga river aside from firemen who found it difficult to access residences due to the very narrow pathway.

Fundamental to the practice of the Bicolano faith is the annual festivity for the Virgin of Penafrancia ending up with the tradition of a river procession for "Ina" the patroness of Bicolandia. The river residents believed that the practice of their faith runs atop any of the river benefit. The sacred tradition comes with the 
conscious awareness that the river will continue to exist with it. This implies that behind the motivation of river sustainability is the perpetuation of the Bicolano's religious culture. It is the Bicolano's faith and tradition that hinders the river state to rest in degradation. It can be further implied that their religious nature makes them the stewards of their river. According to the respondents of barangay Penafrancia they take care of it by watching out for the people who throw their garbage in the river. They are also concerned of erosion that can make their river shallow and be difficult for the passage of "Ina". The ecological value of the river is emphasized through information disseminated by the local government.

FGD sessions revealed that the respondents are aware that a flowing river will stagnate when it becomes polluted and become the basin for waste disposal. As it is today, it is a big drainage system for the entire city where the sewage and effluents run through canals and ends up in the river. Hence, the presence of these river residents is a threat to the existence of the river ecosystem. Similar to the study of Tarranum, F. et.al. (2018), people perceive the river Yamuna in India in a non-scientific way. They perceive the river through their senses specifically according to the uses of the river. The respondents believed that the sources of pollution in the river are the anthropogenic activities which were found to be linked to their direct dependence on the river for their daily needs. In the present study, riverside residents of Naga City are directly dependent on the river for livelihood, domestic use, transport of goods, religious activities, and for recreation purposes.

At present, programs and projects of the city government are slowly educating the river respondents. However they are waiting for a more aggressive action to preserve the river. Their desire to cooperate in local projects, programs and campaigns must be viewed as an opportunity to address the changing environment of the Naga river.

\section{CONCLUSION}

The present study documented the four decades of development of the Naga river through the experiences the respondents had with the river. The Decades of River Excursions (1940s-1950s) was when people felt the high recreational value of the Naga river. Significant in this decade was the straightening of the northeast part of the river instead of its natural curve to build straight and smooth roads in the central part of Naga City. The Decades of Challenges and Uncertainties (1960s-1970s) made the Civic Center the first dump site. Few years after, the dump site was transferred to Magsaysay area now the Avenue Square.
This was also the decade where Colgante Bridge collapsed in 1972 during the Traslacion which killed 140 devotees of INA, the Virgen de Penafrancia. The Decades of River Degradation (1980s-1990s) showed an intensified river degradation. The dump site along Magsaysay Avenue was transferred to barangay Balatas now the "Smokey Mountain" of Naga City. There was a proliferation of residential houses and business establishments which greatly contributed to the pollution. Initiatives to save the river were started primarily by the local government. The Decades of Action (2000s to present) intensified the rehabilitation efforts by the City Government and other concerned groups to revitalize the river. The Revitalization Program was launched, researches to improve the condition of the Naga river were conducted, Feasibility Study on the Integrated Naga River Revitalization Project (INRRP) in 2012 was conducted, Salvar Salog Clean Up Drive was revived, and the relocation of the riverside residents to four relocation sites was done in Naga City.

Perceptions and experiences were likewise determined in terms of shocks and stresses, fears and anxiety, and benefits they derive from the river. The biggest environmental shock and stress experienced by the riverside barangays is the flood brought about by typhoons and heavy rains. Fear of flood is also what the respondents fear most. The riverside households derive benefits from the Naga river which attach them to the river. The primary benefit is the river as a source of their livelihood. This is followed by as a means of transport, use in calamities like fire, a venue for religious activities, and for recreational purposes.

\section{REFERENCES}

1. Blog site of Ateneo de Naga, 1980. The Colgante Bridge Strategy. Sept. 16, 1972.

2. Bordado, G. H. (2011, May 30). Revitalizing the River. City Government of Naga. http://naga.gov.ph/naga-smiles-2/revitalizing-thenaga-river-2.

3. Cities Development Initiative for Asia. (2012, June 14). Executive Summary Naga Pre-Feasibility Study - River Revitalization. www.cdia.asia/2012/06/executive-summary-nagapre-feasibility-study-river-revitalization/

4. City Government of Naga (2012). The Naga City Contingency Plan. https://carbonn.org/uploads/tx_carbonndata/Action \%2016\%20-\%20Disaster\%20Mitigations.pdf

5. DRRMO and CSWDO Naga City (2012). Risk and Hazard Survey.

6. INRRP 2012 Annex B.2 - (Flood Management and Drainage).

7. Elcamel, Ernesto T. "MANAGING URBAN DISASTERS THE NAGA CITY EXPERIENCE ON 
MITIGATION AND PLANNING”. Naga City

Disaster Mitigation Project.Environmental Shocks: as Policy Drivers.

citeseerx.ist.psu.edu/viewdoc/download?doi=10.1.1. 8.

8. Executive Summary Naga Pre-feasibility Study River Revitalization. CITIES DEVELOPMENT INITIATIVES FOR ASIA. www.cdia.asia/2012/06/executive-summary-nagapre-feasibility-study-river-revitalization/

9. Huq, S. Environmental Shocks as Policy Drivers. http://citeseerx.ist.psu.edu/viewdoc/download?doi=1 $0.1 \cdot 1.8 .7998 \&$ rep $=r e p 1 \&$ type $=p d \AA$

10. Naga River Revitalization Project. From Decision to Action and Results.Naga Smiles Magazine, Vol. 1, No. 1, Sept. 2010.

11. Neola, Jason B. Solid Waste Management Office steps up expanded mandate to keep Naga clean, green, and orderly. Naga SMILES Vol. 2 No. 3 p. 3. 2012.

12. Pasion, Cathy. (2007). Managing the Naga City River: Where to Go from Here.

13. Perez, J.B (Ed). (2010, September) Naga River Revitalization Project: From Decision to Action and Results. Naga Smiles Magazine, Vol. 1, No. 1.

14. Philippine Fish Species - List of Common Fish in the Philippines. (2011, May 27). http://philfoodie.blogspot.com/2011/05/philippinefish.html.

15. Reganit, M. P. (2005). Analysis of Community's Coping Mechanisms in Relation to Floods: A Case Study in Naga City, Philippines.

16. The Filipino Traditional Roman Catholic. (2008). http://thefilipinotraditionalromancatholic.blogspot.c om /2008/10/naga-to-be-pilgrim-city.html

17. Tarannum, Fawzia, Kansal, Arun, and Sharma, Prateek. (2018). Understanding public perception, knowledge and behaviour for water quality management of the river Yamuna in India. Official Journal of the World Water Council. April 2018. Volume 20, Issue 2 iwaponline.com

18. Tunstall, Sylvia, Tapsell, Susan \& House, Margaret House (2007). Children's perceptions of river landscapes and play: what children's photographs reveal. Journal on Landscape Research. Volume 29, 2004 - Issue 2. www.tandfonline.com

19. Usamah, M. B (2005). Modeling Floods Events in the Lower Bicol Floodplain. https://webapps.itc. utwente.nl/librarywww/papers2005/msc/ereg/usama h.pdf

20. Victoria, A. (June 28,2009). Environmental Social Perception. Ezine Articles.

http://ezinearticles.com/?Environmental-SocialPerception\&id $=2536990$

21. USAID. (2006). Rapid Socio Ecological Assessment of the Okavango River Basin Communities in Kuando-Kubango Province, Angola. http://salvarsalog.blogspot.com/p/naga-riverrivatalization.html 